\title{
Os reflexos da criação dos speds na sociedade e no mercado
}

Andressa $L$ uiza de 0 liveira

B eatriz de 0 liveira A ndrade

D iscentes do C urso de C iências C ontábeis - UB M

R osângela dos Santos

D ocente do C urso de C iências C ontábeis - UB M

M estre em C iências C ontábeis/UN I G RAN RIO 


\section{Resumo}

A contabilidade é tão antiga quanto à própria história da civilização. E la está ligada às primeiras manifestações humanas, bem como à necessidade social de proteção à posse e à perpetuação e interpretação dos fatos ocorridos. Há escritos históricos que os primeiros registros contábeis constituíam-se em fichas de barro, guardadas em receptáculos de barro, que eram utilizadas na contagem do patrimônio, registrando, dessa forma, o evento ocorrido e auxiliando o controle do patrimônio por parte do proprietário. D iante das transformações ocorridas na sociedade ao longo das décadas e as inúmeras mudanças econômicas, houve a necessidade de um controle mais efetivo e rigoroso no patrimônio das entidades, sejam elas pessoas físicas ou jurídicas. D o outro lado, os governos criaram mecanismos para aprimorar a fiscalização e, assim, aumentar sua arrecadação. Com o surgimento da informática, o avanço da tecnologia da informação e a revolução digital trouxeram também um novo formato para a administração fazendária tanto no controle e na qualidade quanto na veracidade das informações prestadas pelos contribuintes. Percebe-se que a internet é um importante instrumento de apoio aos administradores, aos gestores e aos profissionais da contabilidade, pois utiliza toda essa tecnologia para aprimorar sua gestão no âmbito da tomada de decisões como para atender as obrigações acessórias impostas pele legislação fiscal e tributária. Com o avanço da tecnologia e o grande volume de operações realizadas pelas grandes empresas, tanto as empresas quanto os órgãos fiscalizadores tiveram que acompanhar esse avanço. 0 presente artigo tem como objetivo ressaltar a importância da tecnologia da informação, ressaltando a finalidade dos SPEDS. A metodologia adotada foi pesquisa de campo e entrevista com um contador, estabelecido na cidade de $B$ arra $M$ ansa- $R$ J, atuando na área contábil aproximadamente trinta anos.

Palavras chave: T ecnologia da informação. SPE D s. C ontabilidade. 


\section{Abstract}

A ccounting is as old as the history of civilization itself. It is linked to the first human manifestations, as well as to the social need to protect the possession and perpetuation and interpretation of events. There are historical writings that the first accounting records consisted of clay tiles, stored in clay receptacles, which were used in the counting of the patrimony, recording, in this way, the event occurred and helping the control of the patrimony on the part of the owner. Faced with the changes that have taken place in society over the decades and the numerous economic changes, there has been a need for a more effective and rigorous control over the assets of entities, whether individuals or corporations. $\mathrm{O}$ the other hand, governments have created mechanisms to improve oversight and thus increase their collection. W ith the advent of information technology, the advancement of information technology and the digital revolution also brought a new format for the management of the economy, both in terms of control and quality, as well as the truthfulness of information provided by taxpayers. It is noticed that the internet is an important instrument of support to administrators, managers and accounting professionals, because it uses all this technology to improve its management in the scope of decision making as to meet the ancillary obligations imposed by the tax and tax laws. W ith the advancement of technology and the large volume of operations carried out by large companies, both companies and inspection bodies had to follow up this advance. This article aims to highlight the importance of information technology, highlighting the purpose of SPED s. The methodology adopted was field research and interview with an accountant, established in the city of Barra $M$ ansa-RJ, working in the accounting area for approximately thirty years.

Keywords: Information technology. SPE D s. A ccounting. 


\section{Introdução}

A história da contabilidade é tão antiga quanto a própria história da civilização. Está ligada às primeiras manifestações humanas da necessidade social de proteção à posse e de perpetuação e interpretação dos fatos ocorridos com o objeto material de que o homem sempre dispôs para alcançar os fins propostos. A o deixar a caça, o homem voltou-se à organização da agricultura e do pastoreio. A organização econômica acerca do direito do uso do solo acarretou separatividade, rompendo a vida comunitária, surgindo divisões e o senso de propriedade.

D esse modo, cada pessoa criava sua riqueza individual. A o morrer, o legado deixado por este indivíduo não era dissolvido, mas passado como herança aos filhos ou parentes. A herança recebida dos pais (pater, patris) denominou-se patrimônio. 0 termo passou a ser utilizado para quaisquer valores, mesmo que estes não tivessem sido herdados.

Percebe-se que a origem da C ontabilidade está ligada à necessidade de registros do comércio. $\mathrm{H}$ á indícios de que as primeiras cidades comerciais eram dos fenícios. $\mathrm{A}$ prática do comércio não era exclusiva destes, sendo exercida nas principais cidades da A ntiguidade.

A atividade de troca e venda dos comerciantes semíticos requeria 0 acompanhamento das variações de seus bens quando cada transação era efetuada. As trocas de bens e serviços eram seguidas de simples registros ou relatórios sobre o fato. $M$ as as cobranças de impostos, na Babilônia já se faziam com escritas, embora rudimentares. Um escriba egípcio contabilizou os negócios efetuados pelo governo de seu país no ano 2000 a.C.

Depreende-se que, à medida que o homem começava a possuir maior quantidade de valores, preocupava Ihe saber quanto poderiam render e qual a forma mais simples de aumentar as suas posses. T ais informações não eram de fácil memorização quando já em maior volume, requerendo registros.

Foi o pensamento do futuro que levou o homem aos primeiros registros a fim de que pudesse conhecer as suas reais possibilidades de uso, de consumo, de produção etc. C om o surgimento das primeiras administrações particulares, aparecia a necessidade de controle, que não poderia ser feito sem o devido registro, a fim de que se pudesse prestar conta da coisa administrada. 
É importante lembrar que, naquele tempo, não havia o crédito, ou seja, as compras, vendas e trocas eram à vista. Posteriormente, empregavam-se ramos de árvore assinalados como prova de dívida ou quitação. 0 desenvolvimento do papiro (papel) e do cálamo (pena de escrever) no E gito antigo facilitou extraordinariamente o registro de informações sobre negócios.

À medida que as operações econômicas se tornaram complexas, o seu controle se refinou. As escritas governamentais da República Romana (200 a.C.) já traziam receitas de caixa classificadas em rendas e lucros, e as despesas compreendidas nos itens salários, perdas e diversões. No período medieval, diversas inovações na contabilidade foram introduzidas por governos locais e pela igreja. M as é somente na Itália que surge o termo Contabilitá.

Com o crescimento da riqueza das empresas e a necessidade de um controle mais efetivo por parte de seus gestores e administradores, os governos criaram mecanismos para aprimorar a fiscalização e, assim, aumentar sua arrecadação.

Com o surgimento da informática, o avanço tecnológico e a revolução digital trouxeram um novo formato para administração tributária quanto ao controle, às qualidade e à veracidade das informações prestadas pelos contribuintes. Percebe-se que a internet é importante instrumento de apoio para o gerenciamento das informações, bem como o meio que os gestores, administradores e, principalmente, os profissionais de contabilidade se utilizam dessa tecnologia para aprimorar sua gestão no âmbito da tomada de decisões como também para atender as obrigações acessórias impostas pela legislação fiscal e tributária.

Segundo Souza (2007, p.22), a implementação de tecnologias decorrentes da informatização altera não só a forma de realizar as atividades, mas também traz em seu bojo modificações nas competências exigidas do profissional, decorrentes, em parte, das exigências para operacionalizar o processo de trabalho informatizado e outras decorrentes do atendimento à nova forma de trabalho que elas preceituam.

Com a rapidez e a dinâmica no mundo dos negócios e as exigências fiscais impostas às empresas, o perfil do profissional de contabilidade tem sofrido grandes mutações, não apenas legais, mas também práticas. 0 mercado, a cada dia, exige informações mais detalhadas e em tempo hábil para auxiliar nas tomadas de decisões, tanto gerenciais como também administrativas, financeiras e ainda junto ao fisco. 
D iante de tantas exigências impostas não só para atender aos clientes, mas também ao fisco, as empresas de contabilidade tiveram que investir em tecnologia de informação. A metodologia utilizada neste artigo é a pesquisa bibliográfica e de campo, tendo como objetivo discorrer sobre os principais subsídios dados aos gestores e ao fisco, utilizando a tecnologia de modo eficiente e eficaz, além de apontar o novo perfil do profissional de contabilidade na era digital e tecnológica.

\section{Fundamentação Teórica}

A Tecnologia da Informação evoluiu muito ao longo dos anos. E, se formos nos aprofundar na história, é possível abordar desde a criação da eletricidade em 700 a.c. por T ales de M ileto. A partir daí, começa a surgir a T ecnologia da I nformação, com os primeiros equipamentos de comunicação, acreditando-se que as máquinas poderiam imitar o poder da mente.

A ciência da computação é decorrente de uma necessidade humana, o próprio homem buscou isso com naturalidade, conforme sua necessidade. Podemos citar a criação de máquinas de somar, caixas registradoras e, posteriormente, o surgimento de "programas" de computador, por volta de 1830 , antes mesmo do surgimento do computador, o que retrata as primeiras experiências do homem com a contabilidade.

D urante a Segunda G uerra M undial, ocorreu 0 avanço mais importante para a Tecnologia da Informação que foi o avanço para os computadores eletrônicos e modernos que vemos e utilizamos hoje.

A tualmente, é possível verificar que houve uma grande evolução tecnológica. $D$ as gigantes máquinas criadas no passado, damos um salto para pequenos aparelhos móveis com capacidade para gerir um mundo de informações. 0 mundo respira tecnologia e, grande parte das operações e integração humana, hoje, provém dos meios de comunicação, pois as informações começaram a fluir com mais facilidade.

Com todo esse avanço tecnológico, o profissional de contabilidade que detém todo o conhecimento dessa ciência, que avalia e controla o patrimônio das organizações, para acompanhar toda essa evolução e para manter a competitividade no mercado, teve que mudar seu perfil profissional, adequando-se ao "novo", por meio da utilização da T ecnologia da I nformação na contabilidade. 
A aplicação da Tecnologia da Informação torna todo o processo contábil da empresa mais dinâmico e confiável, porém, ainda é indispensável que a empresa possua um profissional em contabilidade que seja capacitado a gerir todos esses programas e informações produzidos pelas entidades, pois a saúde financeira e suas legalidades com os órgãos fiscalizadores estarão na mão desse profissional contábil, junto aos programas utilizados e por ele geridos.

\title{
A contabilidade e as novas tecnologias de informação
}

\author{
NOTA FISCAL ELETRÔNICA
}

Com 0 avanço da tecnologia e o grande volume de operações realizadas pelas grandes empresas, tanto as empresas quanto os órgãos fiscalizadores tiveram que se adaptar. $M$ as essas modernizações só ocorreram quando os governos Federal, M unicipal e E stadual se uniram, numa ação integrada, para centralizar suas informações. D essa forma, surgiu assim a $\mathrm{N}$ ota $\mathrm{F}$ iscal E letrônica (N F-e).

Segundo, o parágrafo $1^{\circ}$ do ajuste SINIEF 7, de setembro de 2005, a N ota Fiscal Eletrônica é um documento de existência digital, ou seja, armazenado e emitido eletronicamente. Foi criado com a finalidade de documentar a circulação de mercadorias ou prestação de serviços, atendendo às exigências do Fisco e fortalecendo seu controle de fiscalização. Sua autenticidade é comprovada pela assinatura digital do emitente e a autorização de uso fornecida pela administração tributária do contribuinte.

C omo é um documento digital, a $N$ ota $F$ iscal E letrônica substitui a $N$ ota Fiscal que antes era emitida em papel, hoje é entregue, em formato de mensageiro (XM L) , à Receita Federal ou à SEFAZ (Secretaria de Fazenda) do Estado onde é emitida. A $\mathrm{NF}$-e é enviada ao fisco e validada em tempo real, evitando assim possíveis fraudes nas operações com vendas e no pagamento de tributos. Temos ainda a $\mathrm{N}$ ota Fiscal de Serviço Eletrônica ( $\mathrm{F}$ e - serviço), os serviços são sempre tributados no âmbito municipal (ISS), assim cada município possui um padrão diferente, porém com a mesma finalidade, o padrão nacional para a NF e serviço é sempre um documento digital com validade legal e que elimina qualquer tipo de documento físico. 


\section{CERTIFICADO DIGITAL}

Há tempos, as pessoas utilizam assinaturas à caneta com carimbos, selos e outros recursos para comprovar a veracidade dos documentos, porém, com o avanço tecnológico dos dias de hoje, tornou-se possível a realização de muitas dessas atividades por meio da internet, o grande problema seria garantir a veracidade em documentos feitos pela rede, se não fosse mais um grande passo na tecnologia contábil, a criação do Certificado D igital.

A internet permitiu que pessoas, empresas e governos realizassem uma série de procedimentos de maneira fácil, rápida e segura. G raças a essa facilidade, é possível concretizar negociações, emitir ou receber documentos, acessar ou disponibilizar informações sigilosas. No entanto, da mesma forma que os computadores e a internet oferecem meios para benefícios, também podem oferecer meios para fraudes e assim burlar as leis, o que nos leva a concluir que uma transação feita eletronicamente, para se tornar confiável, precisa ser certificada digitalmente.

Inicialmente, a certificação digital é um tipo de tecnologia de identificação que permite que transações eletrônicas dos mais diversos tipos sejam realizadas assegurando sua integridade, sua autenticidade e sua confiabilidade, de forma a se evitar que adulterações e a captura de informações privadas ou outros tipos de fraudes ocorram. Sua funcionalidade é baseada em um documento eletrônico chamado certificado digital e em um recurso denominado assinatura digital.

Certificado digital nada mais é do que um documento eletrônico com assinatura digital que contém dados como nome do utilizador que pode ser uma pessoa, uma empresa ou instituição, pois o certificado já está disponível tanto como CN PJ como CPF. N o certificado, é possível identificar a entidade emissora, seu prazo de validade e a chave pública. Com ele, é possível ter certeza de que a parte interessada está se relacionando com a pessoa ou com a entidade desejada. Um dos moldes de certificado digital mais conhecido vem dos bancos: quando uma pessoa acessa sua conta corrente através da internet, certificados digitais são utilizados para garantir que o cliente de fato esteja realizando transações financeiras com seu banco.

Para o certificado digital ser aceito e utilizado por pessoas, empresas e governos, precisam ser emitidos por entidades apropriadas. Sendo assim, o primeiro passo é procurar uma autoridade certificadora conhecida com AC (Assinatura Certisign). 
E la tem a função de associar uma identidade e inserir os dados no certificado, por isso o solicitante deve fornecer documentos que comprovem sua identificação.

O uso do certificado digital já está completamente associado à realidade brasileira, o que ocasionará, em um futuro bem próximo, o fim total das assinaturas normais, modelo disso é o uso do certificado pelo governo F ederal com o objetivo de dar celeridade e segurança aos processos internos ou para prestar informações sensíveis ao cidadão.

Já os governos $M$ unicipais e $E$ staduais estão em fase final de implantação do sistema, o que fará com que as empresas, ainda não associadas ao modelo, providenciem o seu certificado mais rápido, pois as declarações, não só as de área de tributos como todas as demais envolvidas na contabilidade, necessitarão do certificado para transmitir, receber e consultar informações referentes à entidade analisada.

0 certificado muito facilita o que se relaciona a assinaturas, mas também é muito útil para os contadores, pois, por meio destes é possível verificar como está a situação atual da empresa na Receita Federal, fazendo com que o cliente e a própria contabilidade tenham ciência do que realmente ocorre. Coisas que antigamente demoravam a ser resolvidas entre contador e cliente, hoje podem ser verificadas através de um portal, disponível no site da R eceita F ederal.

\section{SPED - SISTEMA PÚBLICO DE ESCRITURAÇÃO DIGITAL}

D evido ao expressivo aumento do número de novas empresas com os mais variados objetivos sociais, os legisladores brasileiros e o Conselho Federal de C ontabilidade sentiram-se obrigados a se modernizar tecnologicamente. C om o objetivo de padronizar o sistema, utilizando a mesma língua, o D ecreto no 6.022, de 22 de janeiro de 2007 instituiu o SPED - Sistema Público de Escrituração Digital. 0 novo sistema é alimentado por todos os órgãos públicos que transmitem seus dados para 0 banco único, com riqueza de detalhes.

O sistema público de escrituração digital alterou a forma de cumprimento das obrigações acessórias realizadas pelos contribuintes, substituindo a emissão de livros e documentos contábeis e fiscais em papel, por documentos eletrônicos, cuja autoria, integridade e validade jurídica são reconhecidas pelo uso da certificação digital. 
A concepção do SPED teve como objeto a promoção da atuação integrada do fisco. 0 projeto, de acordo com especialistas, é uma das maiores revoluções digitais da contabilidade no Brasil.

E m nosso país, conforme prevê a Constituição $F$ ederal de 1988, os tributos podem ser exigidos pela União, Estados e M unicípios, sendo facultado ao Distrito F ederal exigir os tributos de natureza estadual e municipal.

O SPED, destarte, proporciona a entrega única do que hoje é realizado em várias obrigações acessórias, centralizando em único banco de dados. Isso facilita e racionaliza o fluxo informacional corrente.

Por intermédio de tal sistema, os empresários, sociedades empresariais e contabilistas utilizam assinatura digital com certificação digital no padrão ICP-B rasil. A entrega dos documentos fiscais eletrônicos é feita via internet ou, em caso de contingência, off-line. Para dar suporte jurídico às escriturações fiscais e contábeis digitais e N F-e, são identificados dispositivos legais tanto na esfera comercial como na fiscal.

O Sistema Público de E scrituração D igital se subdivide em vários módulos, exprimindo obrigações acessórias, tais como o regime de E scrituração C ontábil D igital ( ECD ), E scrituração C ontábil Fiscal (ECF), EFD -C ontribuições Pis/Pasep e da C ofins, EFD-ICMS/IPI, Escrituração Fiscal Digital de Retenções e Outras Informações Fiscais EFD-Reinf, SPED eSocial. Assim, a título exemplificativo, a Instrução N ormativa RFB ํ‥ 1420/2013 instituiu que todas as sociedades empresarias e as demais estão obrigadas a Escrituração C ontábil Digital (SPED C ontábil), utilizada para fins fiscais e previdenciários.

C om o SPE D, passa a ser obrigatória a assinatura digital de todas as obrigações acessórias supracitadas. E $m$ cada documento fiscal, é importante ter a assinatura digital para assegurar a sua validade jurídica. Portanto, é imperativo que todos os contribuintes, independentemente do porte da empresa, adquiram o certificado digital. A certificação digital é o mecanismo de segurança capaz de garantir autenticidade, confiabilidade e integridade às informações eletrônicas e documentos trocados na internet por meio da tecnologia de criptografia. É a forma de identificar a autoria nas operações. 


\title{
Principais pilares do \\ SPED - Sistema Público De Escrituração Digital
}

\author{
SPED CONTÁBIL
}

O SPED Contábil entrou em vigor em 2008 e foi entregue pela primeira vez em 2009, substituindo os livros contábeis, como o livro diário e razão, que antes eram escriturados em papel. H oje, todas as empresas que são optantes pelo Lucro Real já podem optar por aderir ao SPED Contábil em substituição aos L ivros Contábeis em papel.

Como gerar um SPED Contábil? 0 arquivo digital do SPED Contábil deve ser entregue em formato texto (txt), de acordo com os padrões estabelecidos pela Receita F ederal do Brasil, em todo último dia útil do mês de junho de cada ano, devendo ser assinado digitalmente pelo contador e também pelo representante legal da empresa, e depois registrado eletronicamente pela J unta C omercial do $\mathrm{E}$ stado.

\section{SPED FISCAL}

O SPED Fiscal entrou em vigor também entre 2008 e 2009, substituindo os L ivros F iscais de entrada e saída e também os inventários, em 2011, substituiu também o controle do CIA P, sendo entregue mensalmente, em conjunto. O SPE D Fiscal foi um dos maiores desafios na implantação do sistema para a gestão Fiscal, pois envolveu pessoas, sistemas e processos, mas alcançou o sucesso.

\section{SPED EFD-CONTRIBUIÇÕES}

A EFD - C ontribuições trata de arquivo digital instituído no Sistema Público de E scrituração D igital - SPED , a ser utilizado pelas pessoas jurídicas de direito privado na escrituração da Contribuição para o PIS/PASEP e da COFINS, nos regimes de apuração não cumulativo e/ou cumulativo, com base no conjunto de documentos e operações representativos das receitas auferidas, bem como dos custos, despesas, encargos e aquisições geradores de créditos da não-cumulatividade. 
Segundo o advento da Lei no 12.546/2011, a EFD-C ontribuições passou a contemplar também a escrituração digital da Contribuição Previdenciária sobre a Receita Bruta, incidente nos setores de serviços e indústrias, no auferimento de receitas referentes aos serviços e produtos nela relacionados.

\section{SPED SOCIAL OU E SOCIAL}

0 projeto instituído pelo governo - que faz a integração da folha de pagamento ao Sistema Público de E scrituração D igital (SPED) e já contempla a emissão de notas fiscais e conhecimentos de transporte, entre outros módulos - permitirá ao governo cruzar as informações de praticamente todas as dimensões da operação empresarial. A partir de agora, as notas fiscais (que indicam as vendas realizadas pelos estabelecimentos), os conhecimentos de transporte (que sinalizam as entradas de estoque nos estabelecimentos) e as operações com folha de pagamento se integrarão numa grande rede de informação que permitirá ao Fisco acompanhar, em tempo real, todas as operações da empresa.

O e-Social é um banco de dados que será abastecido pelos contribuintes com informações da folha de pagamento, obrigações trabal histas, previdenciárias e fiscais. Os entes públicos acessarão nesse banco aquelas informações pertinentes às suas atribuições.

Todos aqueles que contratam mão de obra remunerada serão obrigados a se adequarem ao e-social, seja pessoa jurídica, entes públicos ou pessoa física. As regras também incluem empregadores domésticos.

\section{A importância da contabilidade para as empresas}

A contabilidade hoje exerce um papel muito importante diante da sociedade, principalmente quando se trata da gestão de $\mathrm{M}$ icroempresas e Empresas de Pequeno Porte.

A principal vantagem de ter uma boa contabilidade é a manutenção e gestão da saúde do negócio, ou seja, o equilíbrio entre as receitas e despesas, ativo e passivo da empresa, para que, ao longo do tempo, a empresa consiga remunerar seus sócios e 
cumprir com suas obrigações fiscais, trabal histas e com os fornecedores e ainda com seus clientes, sem que haja nenhum tipo de divergência.

A contabilidade também auxilia e facilita nas tomadas de decisões, sobre investimentos, contratação de pessoas, desenvolvimento de novos produtos ou serviços, campanha de marketing e outras ações que ajudam a alavancar e crescer cada vez mais 0 negócio.

Sabemos ainda que os impostos são indispensáveis para que o governo consiga oferecer condições adequadas para as empresas e pessoas conduzirem suas atividades, portanto, uma gestão empresarial, com a contabilidade estruturada, ajuda a avaliar o melhor regime de tributação em função do momento vivido pela empresa, assim também como o momento de identificar a melhor hora de alterá-lo. Ainda que os empresários queiram pagar menos impostos, adotar a contabilidade como aspecto fundamental do negócio também garante que a empresa cumpra com suas obrigações junto aos órgãos fiscalizadores e ao governo, evitando gastos elevados com multas e atrasos.

\section{Da pesquisa de campo \\ e aspectos metodológicos}

0 objetivo desse tópico é apresentar a estrutura metodológica que serviu como base para este artigo. A lém disso, visa descrever como a metodologia foi utilizada para a apresentação e análise do caso pesquisado.

A metodologia utilizada caracteriza-se, de acordo com Vergara (2007), como pesquisa descritiva, através de uma abordagem qualitativa. Tal tipificação se propõe a apresentar as características e individualidades de fenômenos, ensejando padrões técnicos e estruturados para a coleta de dados. A demais, a pesquisa se valeu de dimensão bibliográfica, com base em material publicado em livros, jornais, revistas, sites na internet, dentre outros meios.

Para o desenvolvimento do presente artigo, foi realizada uma pesquisa de campo na qual se concretizou uma entrevista com um contador da cidade de Barra $M$ ansa-RJ, que exerce a profissão há mais de 30 anos. Em entrevista, o contador foi questionado a respeito da sua opinião sobre evolução digital da contabilidade. 
O contador relatou que sua trajetória profissional iniciou-se quando ainda sequer existia o vocábulo tecnologia. Ele utilizava apenas caneta tinteiro. Em suas lembranças, citou que o diário não poderia em hipótese alguma ter rasuras ou borrões e que se valia de um recurso de molhar o cotonete com água sanitária e passar sobre o erro e o mesmo desapareceria, após um lapso de tempo de secagem.

Foi citado por ele que as guias para pagamento de impostos e contribuições eram feitas por intermédio da máquina de datilografia, depois de calculados em máquina de calcular manuais. Com a evolução, a tinta azul lavável foi substituída pela máquina de datilografia, com tinta copiativa que, após complemento de página por página, era transferida para o diário através de gelatina, as assinaturas eram feitas com lápis cópia.

O utro aspecto abordado pelo profissional foi a criação, pela indústria de máquina $\mathrm{A}$ udit, de uma máquina especial para fazer contabilidade. Tal máquina tinha 0 poder de estampar na folha o diário e totalizar as operações. A mudança do sistema mecanizado para o informatizado por meio de computadores que eram apresentados na figura de grandes máquinas e, a chegada dos microcomputadores implicou para a contabilidade a transição de uma escrituração mecanizada para uma escrituração eletrônica.

A Contabilidade ficou cada vez mais simples e rápida. 0 processamento eletrônico de dados foi fundamental, pois, além de tempo, economizou-se espaço, já que processos antes feitos à mão são armazenados de maneira eletrônica, na memória dos computadores. Assim, foi necessário adequar-se aos avanços tecnológicos para atender, de maneira eficiente e eficaz, o clientes e manter-se competitivo no mercado diante das exigências do fisco, investindo em mão de obra capacitada, buscando assim que seus colaboradores tivessem uma formação sólida em contabilidade com conhecimento das novas tecnologias de informação.

Com a necessidade dos governos Federal, E stadual e M unicipal de melhorar o controle dos processos e a rapidez no acesso às informações e à fiscalização mais efetiva das operações com o cruzamento de dados e auditoria eletrônica, o contador citou que 0 SPED não é apenas um sistema público de escrituração digital, mas também uma nova ordem pública contábil, sendo um instrumento valioso de informações para a tomada de decisões.

Considerando essa nova ordem pública, os usuários da contabilidade terão que se adaptar às novas normas do fisco e ter uma nova postura profissional, qual seja, a de 
gerenciar as informações que são enviadas aos fiscos de modo que possam inibir as infrações aos contribuintes e contribuir de maneira efetiva para melhoria das informações contábeis e fiscais.

\title{
Considerações Finais
}

$\mathrm{N}$ as últimas décadas, aconteceram mudanças significativas na contabilidade e sua legislação brasileira, o processo manual foi substituído pelo mecânico e, logo em seguida, pelo eletrônico. Segundo Vilardaga Vicente (2009, p.14 revista razão contábil),

\begin{abstract}
A contabilidade e o controle fiscal no Brasil estão passando por uma revolução digital, que envolve 0 aumento da transparência sistêmica e o monitoramento fino e remoto da Receita F ederal sobre as operações contábeis e os processos internos das empresas.
\end{abstract}

O Sistema Público de E scrituração D igital (SPE D ), lançado em janeiro de 2007, pelo governo, como parte do Plano de A celeração do C rescimento (PAC), já começa a ocorrer em grande escala e vai levar a substituição gradual do papel pelo meio eletrônico como suporte das informações que garantem o cumprimento das obrigações acessórias. As contas das empresas circularão pela internet na forma de arquivos digitais e 0 trabalho de fiscalização se tornará mais preciso e rápido.

Diante da pesquisa exposta, conclui-se que o uso da tecnologia da informação possibilitará a identificação de recursos que venham cada vez mais maximizar a transparência das empresas, encontrando no Sistema Público de Escrituração D igital SPED um dos melhores e maiores instrumentos, que devem exigir das empresas uma transparência nunca dantes observada. Com a criação da ferramenta dos SPEDs, as empresas terão maior integração administrativa, padronizando e melhorando a qualidade das informações e, ainda, racionalizando os custos da carga de trabalho operacional, que antes era utilizada no atendimento e escrituração dos livros contábeis.

O Sistema Público de Escrituração Digital - SPED trouxe muitos desafios e oportunidades aos profissionais e empresas da área contábil. A antecipação e adaptação a esse novo tipo de sistema tornaram-se uma vantagem competitiva em relação às demais empresas do ramo, gerando um importante diferencial no mundo corporativo e 
diminuindo a concorrência desleal. 0 uso dos recursos tecnológicos a cada dia agrega mais competitividade aos negócios e auxilia os clientes nas tomadas de decisões.

Junto com o novo sistema está também a simplificação do processo, em que não há mais necessidade de imprimir e armazenar livros de registro e escrituração contábil e fiscal, que passam a ser escriturados e autenticados eletronicamente e enviados aos órgãos competentes.

U ma das mudanças que o contabilista deve estar constantemente atento são os SPE D s fiscais. E FD (E scrituração Fiscal D igital) é um arquivo digital, que se constitui de um conjunto de escriturações de documentos fiscais e de outras informações de interesse dos fiscos das unidades federadas e da Secretaria da Receita F ederal do B rasil, bem como de registros de apuração de impostos referentes às operações e prestações praticadas pelo contribuinte.

\section{Referências}

A N D RA DE, E dmar O liveira. Planejamento T ributário. Rio de janeiro: Saraiva 2009.

A ZE VE D O , O smar R eis. Comentários às N ovas R egras C ontábeis Brasileeras, 3. ed. São Paulo: IO B, 2009.

A ZE VE D O , O smar Reis; M A RIA N O, Paulo A ntonio. Sistema Público de E scrituração Digital. 2. ed. São Paulo: IO B, 2009.

BE RA L D I, L airce C astanheira; FIL H O , E dmundo E scravidão. Ci. Inf., B rasília, v. 29, n. 1, p. 46-50, jan./abr. 2000. São Paulo.

BEZ E R RA , José Senador. Código T ributário N acional e L egislação Correlata, R evista do Senado F ederal, 2011.

BRA SI L. D ecreto no 6.022, de 22 de janeiro de 2007. Instituição do Sistema Público de E scrituração D igital. C âmara dos D eputados. D isponível em: < http://www2.camara.leg.br/legin/fed/decret/2007/decreto-6022-22-janeiro-2007549814-normaatualizada-pe.pdf > 
BRA SI L . A juste SIN IE F 7, de 30 de setembro de 2005. Instituição da N ota Fiscal E letrônica. Receita F ederal. D isponível em: < https://www.confaz.fazenda.gov.br/legislacao/ajustes/2005/AJ_011_05_007_05>

BRA SI L, Receita F ederal do, SPE D. D isponível em «tttp://www1.receita.fazenda.gov.br/Sped/>. E SPE RA N D ÍO , A lexandre dos Santos; M E L O, Rodrigo C arlos; M A T A , A Itair Roberto. SPE D : SPE D Fiscal - V antagens e Importância. L ondrina, 2011.

GIM E N EZ, Ricardo; SPE D - C onfira quais são os benefícios, tipos e as dicas fundamentais que sua empresa precisa saber sobre tributação fiscal. São Paulo, 2010.

HIST Ó RIA DA CONTABILIDADE . A Contabilidadena IdadeAntiga বhttps://pt.wikibooks.org/wiki/H ist\%C 3\%B 3ria_da_C ontabilidade/A_C ontabilidade_n a_Idade_A ntiga>.

LAKAT OS, E. M .; M A RC O NI, M . A , F undamentos de M etodologia Científica. São Paulo. Ed. A tlas, 1985.

M A CIE L, Pollyana Flores; SO UZA , M arta A Ives. Os impados do SPE D nas E mpresas de Contabilidade. Belo H orizonte- M G, 2012.

M ARTIN S, Eliseu; GE LBCKE, E rnesto Rubens; LUDICIBUS, Sergio. M anual de Contabilidade Societária - A plicável A T odas As Sociedades - 2. ed. 2013.

PE G AS, Paulo H enrique. M anual de ContabilidadeT ributária. 7. E d. Rio de Janeiro: F reitas B astos, 2011.

SÁ, A ntonio L opes de. A evolução da contabilidade. São Paulo IO B T homson, 2006.

SE FA Z. D isponível em বhttp://www.fazenda.rj.gov.br/sefaz/faces/menu_structure/servicos?_afrL oop=18192811 $7161000 \&$ datasource $=$ UC M Server\%23dD ocN ame\%3A 920009\&_adf.ctrlstate=31vzy0pmm_72>.

SE RA SA . D isponível em «ttps://serasa.certificadodigital.com.br/>. 
VER G A RA, Sylvia C onstant. Projetos e relatórios de pesqui sa em administração. 9 ed. São Paulo: A tlas, 2007.

VILARD A G A, Vicente. R evista R azão Contábil, 2009. 